\title{
Propagule pressure and functional diversity: interactive effects on a macroalgal invasion process
}

\author{
Fátima Vaz-Pinto ${ }^{1,2, *}$, Celia Olabarria ${ }^{3}$, Francisco Arenas ${ }^{1}$ \\ ${ }^{1}$ Laboratório de Biodiversidade Costeira, Centro Interdisciplinar de Investigação Marinha e Ambiental (CIIMAR), \\ Universidade do Porto, Porto 4050-123, Portugal \\ ${ }^{2}$ Instituto de Ciências Biomédicas Abel Salazar (ICBAS), Universidade do Porto, Porto 4050-313, Portugal \\ ${ }^{3}$ Departamento de Ecología y Biología Animal, Facultad de Ciencias del Mar, Universidad de Vigo, Vigo 36310, Spain
}

\begin{abstract}
Invasive species are considered an increasing global threat to marine ecosystems. Understanding which factors can accelerate or reduce invasion success is one of the main goals of invasion ecology. The present study investigated the interactive effects of propagule pressure and native functional diversity on the invasion success of the invasive alga Sargassum muticum (Yendo) Fensholt over a 1 yr invasion process (i.e. settlement, recruitment and colonisation). The invasibility of macroalgal assemblages with different functional diversity was assessed under high and low propagule pressure. Synthetic assemblages resembling natural marine macroalgal assemblages were built and used as model systems. Recruitment discs were used to record early settlement in the assemblages. Recruitment and colonisation success were monitored in the field 2 and 10 mo after exposure to propagule rain in the laboratory. The availability of resources (space and photosynthetically active radiation [PAR]) was also monitored for each assemblage and used as predictive variables in the analyses. The effects of propagule pressure and functional diversity varied among the invasion stages. Space availability did not play a significant role in the recruitment success of the invader. However, PAR was a key resource in its invasion success. Overall, the invasion success of $S$. muticum was influenced differently by different traits of the recipient assemblages. Hence, invasion success may be better explained by the interaction of environmental factors that co-vary with species diversity and identity at different invasion stages.
\end{abstract}

KEY WORDS: Invasion success - Propagule pressure - Resources - Functional diversity · Sargassum muticum $\cdot$ Macroalgae

\section{INTRODUCTION}

Increasing intensity of anthropogenic activities is promoting diversity loss and enhancing the introduction and spread of exotic organisms to new areas outside of their native range (Vitousek et al. 1997, Chapin et al. 2000). Beyond the changes in species range, which occur constantly in nature (Vermeij 1991), it is the accelerating rate and the magnitude of those changes that pose a threat to global biodiversity (Lodge 1993). Linked to human- induced modifications, invasions of non-indigenous species (NIS) all over the world are enhancing habitat homogenisation (Vitousek et al. 1997, Olden \& Poff 2004), with unknown consequences for Earth's biota and ecosystem functioning (Olden et al. 2004).

The invasion process, however, is a very complex phenomenon and consists of several transitional stages (Williamson 2006), such as arrival, establishment and success in spreading. Survivorship through each stage of the invasion process is the 
ultimate goal of any NIS. Understanding which factors influence invasion success through the different stages, and to what extent, is extremely important in invasion ecology (Kolar \& Lodge 2001, White \& Shurin 2007). Overall, 3 factors are usually cited as determining the fate of invasions: the biology of the introduced species (species invasiveness), the number and frequency of introductions (propagule pressure [PP]) and the susceptibility of the native community to invasion (community invasibility) (Lonsdale 1999). Nonetheless, invasion studies are usually focused on only one of these factors (Lonsdale 1999).

It is widely accepted that highly diverse communities are more resistant to invasions because of a more complete utilisation of resources, the socalled biotic resistance theory (see Elton 1958, Levine 2000, Fridley et al. 2007 for a review of diversity-invasibility relationships). For benthic algal communities as sessile photosynthetic organisms, space and light are important limiting resources (Sousa 1979). For example, lack of space and low light availability have been shown to negatively affect the invasion success of the brown macroalga Sargassum muticum (Stæhr et al. 2000, Britton-Simmons 2006). However, there is some ongoing debate about which component of diversity is more relevant in preventing community invasions and the mechanisms involved (e.g. Davis et al. 2000, Arenas et al. 2006, Stachowicz et al. 2007). For example, as a component of biodiversity, functional-group diversity has been suggested to have a greater impact on ecosystem processes than the total number of species per se (Tilman et al. 1997). Moreover, several studies indicate that the composition, i.e. identity effect, of a community may determine its susceptibility to invasion (Symstad 2000, Arenas et al. 2006).

It has been suggested that a large input of propagules is needed for invasion to occur in systems where environmental resistance is strong (D'Antonio et al. 2001). Thus, besides the importance of biotic resistance on the success or failure of invasions, there is a general consensus on the importance of PP (also termed 'introduction effort') as a strong predictor of invasion success (Colautti et al. 2006, Eschtruth \& Battles 2011). PP can be defined as the total number of individuals introduced at a given location (Williamson 1996). This introduction of propagules into a location may occur through several releases. Thus, calculations of PP should include estimates of the number of individuals released in an event, i.e. propagule size, and the number of introduction events, i.e. propagule number (Lockwood et al. 2005). A positive relationship between PP and invasion success has been suggested (Lonsdale 1999, Knights et al. 2012), although the true shape of the relationship is unclear (Lockwood et al. 2005), and its interaction with other factors (e.g. disturbance or resource availability) is mostly unknown (Sakai et al. 2001, BrittonSimmons \& Abbott 2008).

In the present study, we explored how the traits of the recipient assemblage, i.e. functional diversity (FD) and identity, interact with PP to shape the success of an invasion. Our model systems were synthetic macroalgal assemblages with varying levels of FD and, as the invader, we used the Japanese seaweed Sargassum muticum. We tested the hypotheses that PP affects the invasion success of $S$. muticum at different invasion stages and that this effect is shaped by the FD of the recipient native assemblages. Invasibility of macroalgal assemblages is expected to decrease with FD (increased biotic resistance) and increase with greater PP (D'Antonio et al. 2001). In addition, we tested whether the availability of resources (space and photosynthetically active radiation [PAR]) would influence the invasion success.

\section{MATERIALS AND METHODS}

\section{Study area}

Field work was carried out in a large rock pool $(11 \times 2 \mathrm{~m}$, average depth of $35 \mathrm{~cm})$ in the midintertidal shore ( $1.5 \mathrm{~m}$ above chart datum) at Viana do Castelo $\left(41^{\circ} 42^{\prime} 25.72^{\prime \prime} \mathrm{N}\right.$, 8०51'42.71" W, northwest coast of Portugal). The intertidal zone along the Portuguese coastline is influenced by a semidiurnal tidal regime. Native algal assemblages from low shore and rock pools are predominantly of 2 types: (1) understory algae dominated by turf-forming algae (e.g. Corallina spp., Chondracanthus spp., Gelidium spp. and Ceramium spp.) coexisting with encrusting coralline algae like Lithophyllum incrustans and (2) subcanopy species like Bifurcaria bifurcata, Mastocarpus stellatus and Chondrus crispus (Araújo et al. 2006). In the study area, Sargassum muticum is found in mid-intertidal rock pools, lower intertidal channels and subtidal zones. Herbivores include a variety of molluscs, such as snails (mostly Gibbula spp.), limpets (e.g. Patella spp.) and the sea hare Aplysia puntacta Cuvier, 1803 (Monteiro et al. 2009a, 2012). 


\section{The invader, Sargassum muticum}

Sargassum muticum is a marine macroalga native to SE Asia (Yendo 1907). Considered an invasive species all around the world (Norton 1976, Critchley et al. 1983), it is now one of the dominant seaweeds in many low intertidal and subtidal communities along the northern Portuguese coast (Monteiro et al. 2009a). This invasive species is monoecious and selffertile (Norton 1976) and is considered a pseudoperennial alga due to the presence of its lateral branches only for a portion of the year. Reproduction takes place in spring/summer. In the region of study, peak reproduction occurs between mid-April and late July, while senescence of lateral branches begins in mid-June (Arenas et al. 1995). Fertilised eggs are attached to the external surface of the receptacles (reproductive structure) and remain there until the development of tiny germlings with adhesive rhizoids (Norton 1981). After this, the embryo is liberated, sinks and reattaches to the substratum within a few meters of the parent plant (Deysher \& Norton 1982). Adult individuals stay attached to the substratum by a holdfast.

\section{Macroalgal assemblages and experimental design}

Synthetic assemblages were created to manipulate functional group diversity. Based on previous knowledge of macroalgal communities inhabiting rockpools in the northwest coast of Portugal (Araújo et al. 2006, Monteiro et al. 2009a), we selected 3 morphofunctional groups (modified from Steneck \& Dethier 1994): (1) encrusting coralline species, such as Lithophyllum incrustans, (2) turf-forming species from the genera Corallina (usually $5 \mathrm{~cm}$ length) and (3) subcanopy species like Chondrus crispus or Mastocarpus stellatus (may reach $20 \mathrm{~cm}$ length). Small boulders bearing species of the selected morphofunctional groups were collected in the intertidal zone of Viana do Castelo and taken to the laboratory. Using a commercial tile cutter, rock pieces were cut into $2 \times 2 \times 2 \mathrm{~cm}$ cubes and were attached to polyvinyl chloride (PVC) plates using fast-setting underwater cement and screws. Experimental assemblages consisted of $12 \times 17 \times 1 \mathrm{~cm}$ PVC plates with 16 pieces of rock surrounded by $1 \mathrm{~cm}$ PVC pieces for support and protection (Fig. 1). Each rock piece represented 1 functional group characterised by a percentage of cover $>50 \%$ or, in the case of subcanopy species, the presence of $\geq 1$ adult individuals was considered a representation of that functional group.

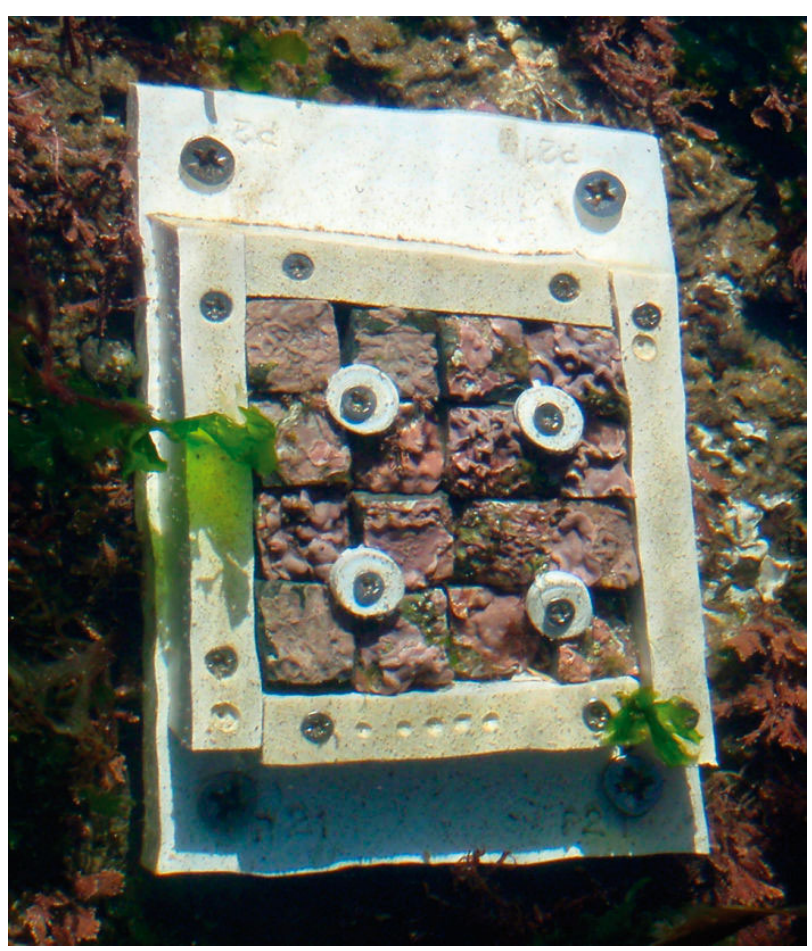

Fig. 1. A macroalgal assemblage plate used in the present study, in this case a monospecific assemblage of encrusting species

Although synthetic and relatively small assemblages were used, these assemblages resembled quite realistically the patchy pattern of intertidal algal assemblages, in which extremely small spatial scales of variation $(<20 \mathrm{~cm})$ seem to be among the most important sources of heterogeneity (Archambault \& Bourget 1996).

Additionally, 4 recruitment discs $\left(1.13 \mathrm{~cm}^{2}\right.$ each) were placed in each assemblage plate for assessment of Sargassum muticum early settlement. A total of 60 plates $(n=4)$ were built: 12 plates of only bare rock, 36 plates with only 1 functional group and 12 plates with 3 functional groups. The spatial distribution of the 3 functional groups within plates was random.

A 2-way factorial design was used to examine the interactive effects of FD and PP on different invasion stages (i.e. settlement, recruitment and colonisation). Both FD and PP were orthogonal fixed factors $(n=4)$. FD incorporated 4 levels: (1) monospecific assemblages of encrusting species, (2) monospecific assemblages of turf-forming species, (3) monospecific assemblages of subcanopy species and (4) 3 functional groups, i.e. high FD. In addition, we also prepared bare rock plates as controls. PP had 3 levels: (1) control/none, (2) low density and (3) high density. 


\section{Invasion procedure}

PP level, here regarded as the density of propagule rain from the introduced species used in a single invasion event, was manipulated by placing different amounts of fertile individuals of Sargassum muticum (high density $\approx 25 \mathrm{~kg}$; low density $\approx 13 \mathrm{~kg}$; control = none) floating over the macroalgal assemblages. To do so, fertile individuals of $S$. muticum were collected from the field and transported to the laboratory, where they were rinsed with fresh water to eliminate grazers. To assure effectiveness of the PP treatment, only individuals with receptacles bearing exuded propagules were used. Experimental invasion was programmed to be around the new moon (22 July 2009) due to the semilunar periodicity of egg expulsion in S. muticum around new or full moons (Norton 1981, Monteiro et al. 2009b). Three tanks of $\sim 300 \mathrm{l}$ of seawater (i.e. 1 tank per treatment) were used for the experiment. A total of 20 macroalgal assemblages, 4 of each assemblage type plus bare rock plates, were randomly assigned to control, low and high PP treatments. Assemblage plates remained in experimental tanks for $1 \mathrm{wk}$. During the invasion procedure, S. muticum individuals remained at the low PP treatment for $3 \mathrm{~d}$ and at the high density treatment for $5 \mathrm{~d}$. Additionally, 10 recruitment discs $\left(5.11 \mathrm{~cm}^{2}\right)$ placed between assemblages in the tanks were used to assess the rain of propagules in each PP treatment. Low propagule rain consisted of an average $(\mathrm{n}=10)$ of $195 \pm 7.72$ ( \pm standard error [SE]) germlings $\mathrm{cm}^{-2}$, while the high density level was $\sim 786 \pm 30.14( \pm \mathrm{SE})$ germlings $\mathrm{cm}^{-2}$.

Assemblages from the control treatment were used to check for invasion by Sargassum muticum individuals in the field. Synthetic assemblages were transported to Viana do Castelo after laboratory experimental manipulation (control plates at Day 6 and plates from PP treatments at Day 8). Assemblage plates were randomly placed and screwed to the bottom of a large intertidal rock pool, separated by $\sim 50 \mathrm{~cm}$, where they remained for 12 mo. The selected rock pool was $S$. muticum free, as all of the individuals had been ripped off by their holdfasts days before the start of the experiment. During the course of the experiment, the rock pool was continuously monitored, and new individuals of $S$. muticum were removed with a scraper.

\section{Measurements of invasibility and sampling procedure}

Invasion of Sargassum muticum was monitored over 3 stages of invasion: settlement, recruitment and colonisation. Settlement of $S$. muticum germlings was assessed 2 to $4 \mathrm{~d}$ after laboratory exposure to propagule rain, prior to transportation of assemblage plates to the field. Recruitment discs from each assemblage plate were used to record germling densities with the use of a stereomicroscope with additional dimmed light. Plates were then transported to the field. To assess the effect of transport, 26 additional recruitment discs (13 per PP treatment) with known densities of $S$. muticum germlings were taken to the field and then returned to the laboratory, where germlings were recounted. Mortality rate $( \pm \mathrm{SE})$ due to transportation $(4.3 \pm 0.91 \%)$ was insignificant when compared to the 2 mo field natural mortality rate of $\sim 99 \%( \pm 0.34)\left(F_{1,50}=2673.16, \mathrm{p}<\right.$ $0.0001)$. Thus, mortality due to transportation was not taken into account when interpreting the results.

Two months after the laboratory exposure to propagule rain (September 2009), recruits were visible to the naked eye, and recruitment was assessed by counting Sargassum muticum recruits in the assemblage plates at the substratum level. Colonisation success was assessed by quantifying adult $S$. muticum (>20 cm length) survivorship in assemblage plates from September 2009 to April 2010.

In addition, we estimated the percentage cover of algae (primary and secondary cover) and bare rock surface. Algal cover was estimated by visually dividing each rock cube in 4 and attributing a score from 0 to 4 for the functional groups present and adding up the 16 estimates (Dethier et al. 1993). The above canopy area was measured as secondary cover when subcanopy species were present.

Available resources (space and PAR) were also monitored for each macroalgal assemblage prior to the invasion procedure. Space availability was assessed during algal cover monitoring by quantifying the percentage of bare rock at the substratum level. PAR penetration (measured as the ratio of PAR under the algal canopy to that above it, or in the case of the encrusting species functional group, at the substratum level to the level $10 \mathrm{~cm}$ above it) was registered with a spherical quantum scalar irradiance sensor (1.9 cm diameter sensor, QSL-2100 Biospherical Instruments). PAR availability at substratum level was related to the irradiance intercepted per functional group and represented a measure of how much PAR reached the substratum. Experimental plates were submerged in a 51 tank during PAR availability measurements. For each plate, the sensor was moved throughout the substrata (below assemblage canopy) and $10 \mathrm{~cm}$ above (or over the assemblage canopy) for $30 \mathrm{~s}$ each. 


\section{Statistical analyses}

Differences in resource availability among FD treatments were assessed with a 1-way analysis of variance (ANOVA). FD was a fixed factor with 4 levels (i.e. encrusting, turf, subcanopy and high FD). Both space and PAR data had homogeneous variances (Cochran's test, $C=0.3518$ and $C=0.3511$, respectively; $\mathrm{p}>0.05$ )

No Sargassum muticum recruitment was recorded in plates from the control PP treatment over the 12 mo experimental period. All new $S$. muticum recruits counted were assumed to come from the laboratory artificial invasion, and thus analyses were only performed for low and high PP treatments. Generalised linear models (GLM) were fitted for settlement and recruitment data to investigate the influence of the explanatory variables on the variation in the number of $S$. muticum germlings and recruits, respectively. For both sets of count data, we assumed a negative binomial distribution (an extension of GLM) to account for high overdispersion using the glm.nb function from the MASS package (Venables \& Ripley 2002). Colonisation success was assessed with presence-absence data, in which 1 represented survivorship of $S$. muticum, and 0 represented no $S$. muticum survivorship to adult stage. For presence-absence data, we used a binomial GLM and a logit link function. Initial fitted models were built using PP (2 levels, high vs. low), FD (5 levels: bare rock, monospecific assemblages of encrusting species, monospecific assemblages of turf-forming species, monospecific assemblages of subcanopy species and high FD assemblages) and 2 continuous variables, PAR and space, as predictors. The continuous variable space availability was not included in the predictive model performed for settlement due to the use of recruitment discs in this stage. We also included biologically reasonable 2-way interactions in the initial model.

To obtain the minimum adequate model, we performed stepwise variable selection minimising Akaike's information criterion (AIC) and then hypothesis testing (Zuur et al. 2009). A posteriori contrasts were performed to assess the statistical significance of differences between the various levels of the categorical factor FD (Crawley 2009). To assess collinearity between variables, we calculated the variance inflation factor (VIF) with the vif function in the car package (Fox \& Weisberg 2011). All VIF values were below 8, indicating low collinearity, so we kept all variables in the analyses. Residuals from the selected model were plotted against the fitted values for model validation.

Rates of instantaneous mortality of the invader were used to test whether or not the mortality rates were constant over the different invasion stages and were calculated following Viejo et al. (1999):

$$
\ln \left[\left(N_{t} / N_{t 0}\right)+0.0001\right] / t
$$

where $N_{t} / N_{t 0}$ is the proportion surviving per macroalgal assemblage, and $t$ is the time after invasion $(0$ to 2 mo: settlement period; 2 to 6 mo: recruitment period; 6 to 12 mo: colonisation period). At the end of the experiment, 2 of the 60 experimental plates were lost due to rough weather, and thus the colonisation data were analysed with 3 replicates instead of the initial 4 in 2 treatments. The design was balanced by adding the averaged values of the other 3 replicates to the model and recalculating the F-values (see Underwood 1997). Rates of instantaneous mortality were analysed with a 3-way ANOVA with PP (2 levels), time (3 levels) and FD (5 levels) as orthogonal fixed factors. Variance was homogeneous (Cochran's test, $C=0.1109$; p > 0.05).

GLMs were carried out using R 2.12.1 (R Development Core Team 2010). ANOVA for resource availability and instantaneous mortality was performed with WinGMAV 5 (Underwood \& Chapman 1998).

\section{RESULTS}

\section{Resource availability}

PAR availability at the substratum level varied significantly among FD treatments (ANOVA, $F_{3,28}$ $=35.20, \mathrm{p}<0.001)$. Monospecific assemblages of encrusting species showed the greatest values of PAR reaching the substratum level (Fig. 2a). PAR availability was particularly low for assemblages composed of subcanopy species, i.e. monospecific assemblages of subcanopy species and assemblages with high FD, whereas assemblages of turf-forming species showed intermediate levels (Fig. 2a).

Space availability varied significantly among FD treatments (ANOVA, $F_{3,28}=29.52, \mathrm{p}<0.0001$ ). Monospecific assemblages of subcanopy species and turf-forming species presented around 40 and $30 \%$, respectively, of bare rock surface, while monospecific assemblages of encrusting species exhibit the lowest values $(\sim 9 \%)$. Plates assembled with the 3 functional groups presented intermediate levels of availability of primary space (Fig. 2b). 

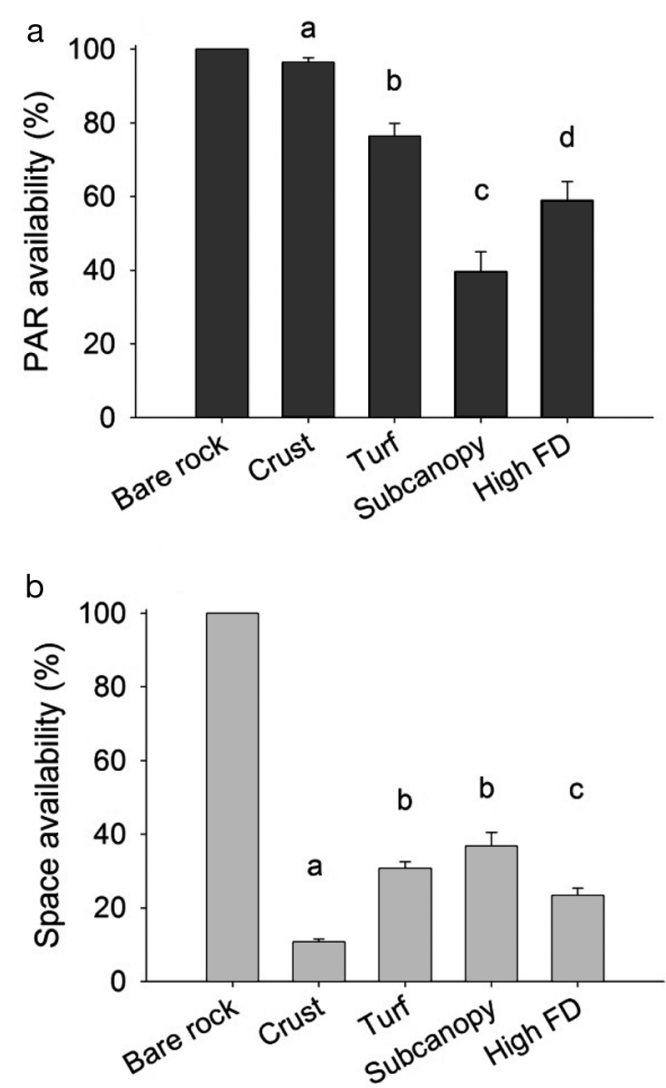

Fig. 2. Availability of resources (mean $+\mathrm{SE}, \mathrm{n}=8$ ) at the substratum level over the different functional diversity treatments, including those made only of bare rock. FD: functional diversity. (a) Photosynthetically active radiation (PAR) availability; (b) space availability as percentage cover of bare rock. Different letters indicate significant differences at $\mathrm{p}<0.05$

\section{Invasion success at different invasion stages}

Invasion success of Sargassum muticum was partially explained by some of the predictive variables included in the models, namely $\mathrm{PP}, \mathrm{FD}$ and PAR availability. However, the variables included in the minimum adequate models differed among the 3 stages of invasion, i.e. settlement, recruitment and colonisation. A different order of inclusion of the variables did not affect the results.

Abundances of Sargassum muticum individuals in the different experimental treatments for the different stages of invasion are presented in Fig. 3. Settlement of $S$. muticum germlings was interactively influenced by PP and functional group diversity (Table 1a), with much higher settlement in high PP treatments (Fig. 3a). Overall, the explanatory variables from the model explained $~ 92 \%$ of the variability in the number of $S$. muticum settled germlings
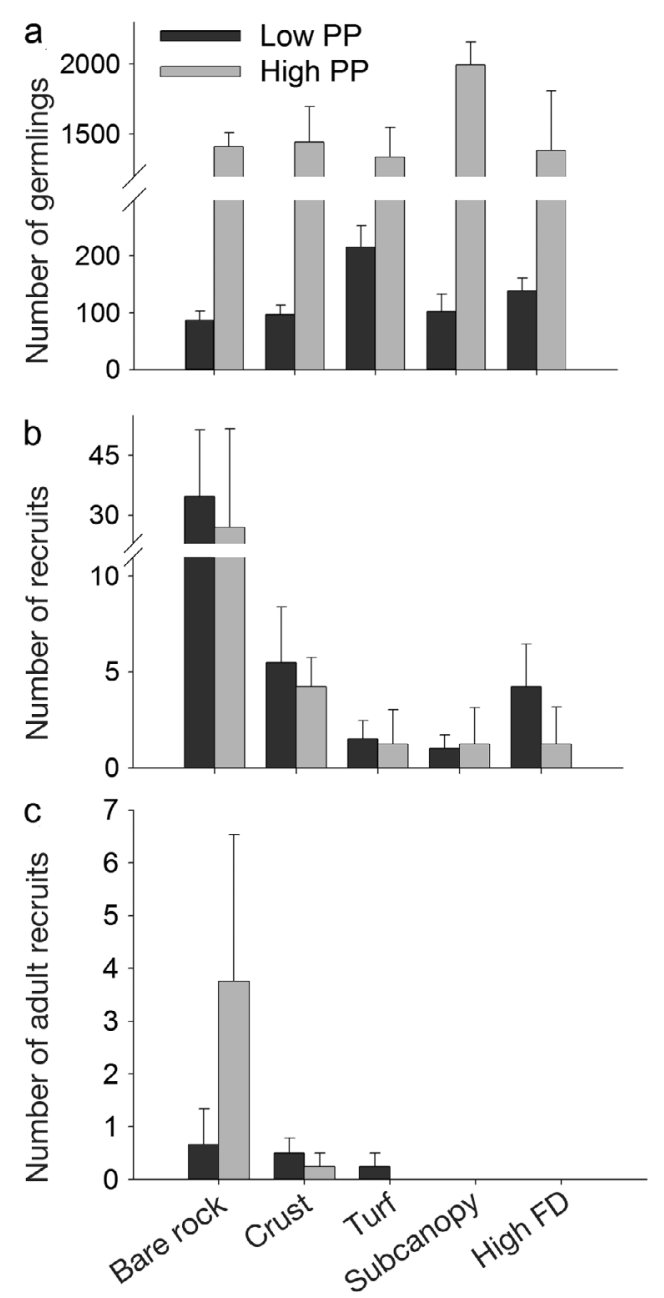

Fig. 3. Sargassum muticum. (a) Settlement (per $2.26 \mathrm{~cm}^{2}$ ), (b) recruitment (per $64 \mathrm{~cm}^{2}$ ) and (c) colonisation (per $64 \mathrm{~cm}^{2}$ ). Mean (+SE, $\mathrm{n}=4$ per functional group and bare rock) number of individuals on assemblages of different functional diversity, including those made only of bare rock. FD: functional diversity; PP: propagule pressure

(Table 1a). The interactive effects of PP and FD resulted in significantly contrasting numbers of settled germlings between macroalgal assemblages at low and high PP. In the low PP treatment, monospecific assemblages of turf-forming species and high FD assemblages registered significantly more settled germlings compared to the other assemblages (Fig. 3a). However, in the high PP treatment, the opposite pattern was observed (Fig. 3a).

Unlike the results observed for the settlement stage, PP was not a significant predictor of Sargassum muticum recruitment success. Thus, the fitted model for recruitment data, i.e. S. muticum juveniles recorded on assemblages at substratum level, inclu- 
Table 1. Analysis of deviance revealed by generalised linear models fitted to the explanatory variables propagule pressure (PP), functional diversity (FD), photosynthetically active radiation (PAR) and space availability. Variable parameters are described for the minimum adequate model for the response variables (a) number of Sargassum muticum germlings, (b) number of $S$. muticum recruits and (c) presence-absence data for survivorship of $S$. muticum to adult stage. AIC: Akaike's information criterion

\begin{tabular}{|c|c|c|c|c|c|c|}
\hline Variables & df & Deviance & Residual df & Residual deviance & $\mathrm{p}$ & AIC \\
\hline \multicolumn{7}{|l|}{ a) Settlement } \\
\hline Model & & & 39 & 498.68 & & \\
\hline $\mathrm{PP}$ & 1 & 434.47 & 38 & 64.21 & $<0.0001$ & \\
\hline FD & 4 & 9.12 & 34 & 55.09 & 0.058 & \\
\hline PP:FD & 4 & 14.28 & 30 & 40.81 & 0.006 & \\
\hline Minimum adequate model & & & & & & 530.77 \\
\hline Full model: & & & & & & 531.43 \\
\hline \multicolumn{7}{|c|}{$\mathrm{PP} \times \mathrm{FD}+\mathrm{PAR}+\mathrm{PP}: \mathrm{PAR}+\mathrm{FD}: \mathrm{PAR}$, family = negative binomial } \\
\hline \multicolumn{7}{|c|}{ b) Recruitment } \\
\hline Model & & & 39 & 88.372 & & \\
\hline FD & 4 & 46.302 & 35 & 42.070 & $<0.0001$ & \\
\hline Minimum adequate model & & & & & & 209.7 \\
\hline Full model: & & & & & & 228.57 \\
\hline \multicolumn{7}{|c|}{ PP $\times$ FD + PAR + Space + PP:PAR + PP:Space + FD:PAR + FD:Space, family = negative binomial } \\
\hline \multicolumn{7}{|c|}{ c) Colonisation } \\
\hline Model & & & 39 & 42.653 & & \\
\hline PAR & 1 & 15.425 & 38 & 27.228 & $<0.0001$ & \\
\hline Minimum adequate model & & & & & & 31.29 \\
\hline \multicolumn{6}{|c|}{ Full model: } & 53.44 \\
\hline \multicolumn{7}{|c|}{$\mathrm{PP}+\mathrm{FD}+\mathrm{PAR}+$ Space + PP:FD + FD:PAR, family = binomial } \\
\hline
\end{tabular}

ded only FD as a significant predictor and explained $52.4 \%$ of the variability in the number of $S$. muticum recruits (Table 1b). In particular, bare rock assemblages had significantly higher number of recruits than the other assemblage types (Fig. 3b).

At the colonisation stage, the survivorship of Sargassum muticum was mainly influenced by PAR availability at the substratum level (Table 1c). Survivorship of $S$. muticum to the adult stage was only observed at high PAR availability (Fig. 4).

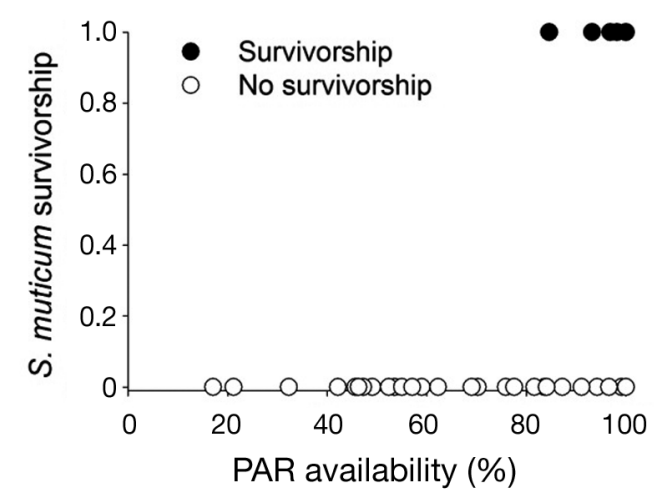

Fig. 4. Sargassum muticum. Colonisation success: variation in the survivorship of $S$. muticum to adult stage (from 2 to $9 \mathrm{mo}$ ) with photosynthetically active radiation (PAR) availability at substratum level on macroalgal assemblages

\section{Instantaneous mortality rates}

The instantaneous mortality rate varied over time independently from the FD of assemblages or PP (ANOVA, p $<0.0001$; Table 2). Post hoc multiple comparisons showed that instantaneous mortality rates were significantly greater during the first 2 mo (mortality of settlers) than over the recruitment period (2 to 12 mo after invasion). In addition, instantaneous mortality rates were also greater in the first 4 mo (2 to 6 mo after invasion) compared to the last 6 mo of the experiment (Fig. 5).

Table 2. Results of the 3-way ANOVA testing for the effects of PP, time (T) and FD on rates of instantaneous mortality of Sargassum muticum. *Two missing replicates were replaced by the average value of the 3 replicates remaining in the treatment, and $2 \mathrm{df}$ were subtracted from residuals

\begin{tabular}{|lcrrc|}
\hline Source & df & MS & \multicolumn{1}{c|}{$F$} & \multicolumn{1}{c|}{$\mathrm{p}$} \\
\hline $\mathrm{PP}$ & 1 & 0.082 & 0.11 & 0.741 \\
$\mathrm{~T}$ & 2 & 136.747 & 177.22 & $<0.0001$ \\
$\mathrm{FD}$ & 4 & 0.112 & 0.14 & 0.967 \\
$\mathrm{PP} \times \mathrm{T}$ & 2 & 0.209 & 0.27 & 0.764 \\
$\mathrm{PP} \times \mathrm{FD}$ & 4 & 0.076 & 0.10 & 0.982 \\
$\mathrm{~T} \times \mathrm{FD}$ & 8 & 0.712 & 0.92 & 0.504 \\
$\mathrm{PP} \times \mathrm{T} \times \mathrm{FD}$ & 8 & 1.433 & 1.86 & 0.076 \\
Residuals & $88^{*}$ & 0.772 & & \\
\hline
\end{tabular}




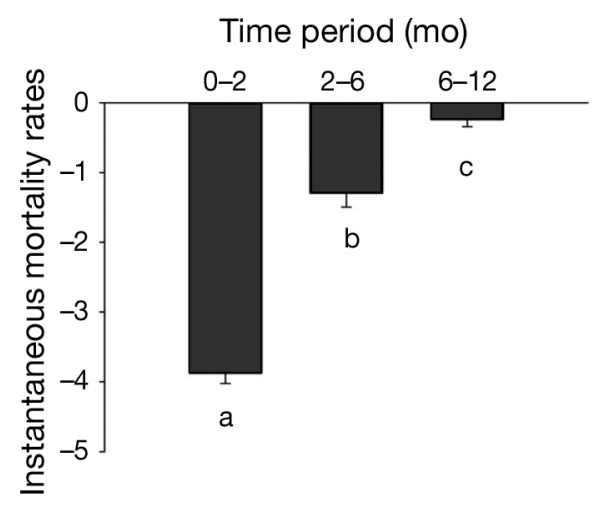

Fig. 5. Sargassum muticum. Instantaneous mortality rates (mean $+\mathrm{SE}, \mathrm{n}=40)$ during the settlement (0 to $2 \mathrm{mo}$ ), recruitment ( 2 to $6 \mathrm{mo}$ ) and colonisation period (6 to $12 \mathrm{mo}$ after invasion). Different letters indicate significant differences at $\mathrm{p}<0.05$

\section{DISCUSSION}

The main and interactive effects of PP and the functional structure of assemblages varied over the different stages of invasion, i.e. settlement, recruitment and colonisation. Moreover, PAR availability at the substratum level was an important variable explaining the invasion success of Sargassum muticum. In contrast to previous studies of $S$. muticum (e.g. Stæhr et al. 2000, Britton-Simmons 2006), space availability did not play a significant role in explaining the recruitment success of the invader.

The role of PP in the invasion process was only relevant over the settlement stage (Clark \& Johnston 2009). Although a high percentage cover of canopy, i.e. monospecific assemblages of subcanopy species, may act as increased biotic resistance under low PP, high PP seemed to overwhelm biotic resistance to invasion. The swaying of the algal fronds induced by water movement could free the substratum they covered, allowing propagules to reach the substratum. Here, because of the use of discs for settlement assessment, it was impossible to separate and model the effect of space availability on the number of settled germlings. Over the settlement stage, the observed larger number of Sargassum muticum germlings in algal turfs than in areas covered by encrusting species has also been registered for Cystoseira spp. (Fucales, Phaeophyta) (Benedetti-Cecchi \& Cinelli 1992). Explanations, such as the idea that algal turf might provide a refuge from water displacement (Brawley \& Johnson 1991) or from herbivores (Benedetti-Cecchi \& Cinelli 1992), are not applicable within laboratory-based artificial invasion.
During the process of settlement, propagules have first to locate the substratum and then to establish surface contact (Fletcher \& Callow 1992). Hence, a possible explanation is that the highly compacted algal turfs entrapped the germlings (Fletcher \& Callow 1992), allowing a higher probability of surface contact. In contrast, greater biomass of subcanopy species could either prevent $S$. muticum germlings from reaching the substratum (Deysher \& Norton 1982) or remove germlings due to scour (Vadas et al. 1992). Nevertheless, the results suggest that the positive effect of turf in highly diverse assemblages could exceed the negative effect of subcanopy fronds. It is possible that $S$. muticum could settle over the fronds (Deysher \& Norton 1982), but that information was not substantiated in the present study. However, no recruits were observed over fronds later on.

The invader, Sargassum muticum, presents a highly successful reproductive strategy by releasing large amounts of germlings intermittently at intervals of $\sim 15 \mathrm{~d}$ throughout its fertile period (Fletcher 1980, Norton 1981). This strategy significantly increases the chances of at least one release coinciding with favourable conditions for settlement, as suggested by studies manipulating disturbance (BrittonSimmons \& Abbott 2008, Clark \& Johnston 2009). Several studies have reported that space and light availability are important resources limiting $S$. muticum recruitment (Andrew \& Viejo 1998, BrittonSimmons 2006, Stæhr et al. 2000). The results from the present study, however, suggest that the number of $S$. muticum at recruitment stage is not significantly affected by either resource. Nonetheless, the fact that bare rock plates showed the greatest number of $S$. muticum recruits suggests that space availability is a determinant for germling settlement. Encrusting species have been described as suitable settlement substrate in some studies (Ang 1985, Arenas et al. 2006), while in other studies they have been suggested to act as an effective barrier to colonisation (Deysher \& Norton 1982). In the present study, monospecific assemblages of encrusting species had the second greatest number of $S$. muticum recruits, highlighting the suitability of encrusting species as a substratum for $S$. muticum. In fact, these results corroborate our field observations that indicate the presence of $S$. muticum adults over a crustose substratum. The structure of assemblages explained $\sim 52 \%$ of $S$. muticum recruitment; the other $50 \%$ may be related to other factors, such as nutrient availability, herbivory or wave action.

The colonisation success of Sargassum muticum was positively affected by the percentage of PAR 
reaching the substratum. This result, together with the fact that monospecific assemblages of subcanopy species significantly decreases the percentage of PAR reaching the substratum, suggests that high values of canopy biomass may have a negative effect on the invader survivorship. Kendrick (1994) indeed showed that canopy significantly affects the survival of recruits $>6$ mo of age, possibly explaining our nonsignificant results for 2 mo old recruits regarding PAR availability.

Although highly diverse communities are expected to achieve a more complete utilisation of resources (the complementary resource-use hypothesis), our experiment based on functional attributes of species provided little support for that. Nonetheless, colonisation of Sargassum muticum was more successful in less complex assemblages, i.e. monospecific assemblages of encrusting species, which presented higher levels of both of the studied resources, PAR and space availability. Additionally, the rate of instantaneous mortality of $S$. muticum was significantly greater during the first 2 mo of age, indicating that early postsettlement processes are decisive in terms of overall invasion success. This fact suggests that postsettlement mortality that is not related to our predictors (e.g. density dependent mortality) eliminates the effect of PP in the final success of the invasion.

Overall, our results did not support the theory that more diverse assemblages are less susceptible to invasion by non-native species (Elton 1958, Lodge 1993, Naeem et al. 2000). However, the inherent traits of each functional group have strong effects on specific resources (Symstad 2000, Britton-Simmons 2006). This fact and our results suggest that the additive effects of each functional role in highly diverse assemblages are important in modifying resource availability and may therefore interfere with community invasibility (Arenas et al. 2006). Our findings show that the invasion success of Sargassum muticum over the different invasion stages is influenced differently by different recipient assemblage traits (Davis et al. 2000, D'Antonio et al. 2001). Throughout the invasion process, resource quality may be just as important as resource quantity, as previously implied by Clark \& Johnston (2009). Hence, the interaction of environmental factors that co-vary with species diversity and identity may better explain invasion success (Eschtruth \& Battles 2009).

Acknowledgements. The authors thank E. Cacabelos, R. C. Vaz-Pinto and D. Villegas for help with the field work. We are also thankful to 4 anonymous reviewers for their constructive comments and suggestions. This research was funded by the AXA Marine Alien and Climate Change project. F.V.-P. is supported by a PhD grant from the Portuguese Foundation for Science and Technology (FCT) (SFRH/BD/ 33393/2008).

\section{LITERATURE CITED}

Andrew NL, Viejo RM (1998) Ecological limits to the invasion of Sargassum muticum in northern Spain. Aquat Bot 60:251-263

> Ang PO Jr (1985) Studies on the recruitment of Sargassum spp. (Fucales: Phaeophyta) in Balibago, Calatagan, Philippines. J Exp Mar Biol Ecol 91:293-301

> Araújo R, Pinto IS, Bárbara I, Quintino V (2006) Macroalgal communities of intertidal rock pools in the northwest coast of Portugal. Acta Oecol 30:192-202

Archambault P, Bourget E (1996) Scales of coastal heterogeneity and benthic intertidal species richness, diversity and abundance. Mar Ecol Prog Ser 136:111-121

Arenas F, Fernández C, Rico JM, Fernández E, Haya D (1995) Growth and reproductive strategies of Sargassum muticum (Yendo) Fensholt and Cystoseira nodicaulis (Whit.) Roberts. Sci Mar 59:1-8

> Arenas F, Sánchez I, Hawkins SJ, Jenkins SR (2006) The invasibility of marine algal assemblages: role of functional diversity and identity. Ecology 87:2851-2861

Benedetti-Cecchi L, Cinelli F (1992) Effects of canopy cover, herbivores and substratum type on patterns of Cystoseira spp. settlement and recruitment in littoral rockpools. Mar Ecol Prog Ser 90:183-191

Brawley SH, Johnson LE (1991) Survival of fucoid embryos in the intertidal zone depends upon developmental stage and microhabitat. J Phycol 27:179-186

Britton-Simmons KH (2006) Functional group diversity, resource preemption and the genesis of invasion resistance in a community of marine algae. Oikos 113: 395-401

Britton-Simmons KH, Abbott KC (2008) Short- and longterm effects of disturbance and propagule pressure on a biological invasion. J Ecol 96:68-77

> Chapin FS III, Zavaleta ES, Eviner VT, Naylor RL and others (2000) Consequences of changing biodiversity. Nature 405:234-242

> Clark GF, Johnston EL (2009) Propagule pressure and disturbance interact to overcome biotic resistance of marine invertebrate communities. Oikos 118:1679-1686

> Colautti RI, Grigorovich IA, MacIsaac HJ (2006) Propagule pressure: a null model for biological invasions. Biol Invasions 8:1023-1037

Crawley MJ (2009) The R book. John Wiley \& Sons, Chichester

> Critchley AT, Farnham WF, Morrell SL (1983) A chronology of new European sites of attachment for the invasive brown alga, Sargassum muticum, 1973-1981. J Mar Biol Assoc UK 63:799-811

D'Antonio C, Levine JM, Thomsen M (2001) Ecosystem resistance to invasion and the role of propagule supply: a California perspective. J Mediterr Ecol 2:233-245

> Davis MA, Grime JP, Thompson K (2000) Fluctuating resources in plant communities: a general theory of invasibility. J Ecol 88:528-534

> Dethier MN, Graham ES, Cohen S, Tear LM (1993) Visual versus random-point percent cover estimations: 'objective' is not always better. Mar Ecol Prog Ser 96:93-100 
Deysher L, Norton TA (1982) Dispersal and colonisation in Sargassum muticum (Yendo) Fensholt. J Exp Mar Biol Ecol 56:179-195

Elton CS (1958) The ecology of invasions by animals and plants. University of Chicago Press, Chicago, IL

Eschtruth AK, Battles JJ (2009) Assessing the relative importance of disturbance, herbivory, diversity, and propagule pressure in exotic plant invasion. Ecol Monogr 79: 265-280

Eschtruth AK, Battles JJ (2011) The importance of quantifying propagule pressure to understand invasion: an examination of riparian forest invasibility. Ecology 92: 1314-1322

Fletcher RL (1980) Studies on the recently introduced brown alga Sargassum muticum (Yendo) Fensholt. III. Periodicity in gamete release and 'incubation' of early embryo stages. Bot Mar 23:425-432

> Fletcher RL, Callow ME (1992) The settlement, attachment and establishment of marine algal spores. Eur J Phycol 27:303-329

Fox J, Weisberg S (2011) An R companion to applied regression, 2nd edn. Sage Publications, Thousand Oaks, CA

- Fridley JD, Stachowicz J, Naeem S, Sax DF and others (2007) The invasion paradox: reconciling pattern and process in species invasions. Ecology 88:3-17

Kendrick GA (1994) Effects of propagule settlement density and adult canopy on survival of recruits of Sargassum spp. (Sargassaceae: Phaeophyta). Mar Ecol Prog Ser 103: 129-140

Knights AM, Firth LB, Walters K (2012) Interactions between multiple recruitment drivers: post-settlement predation mortality and flow-mediated recruitment. PLoS ONE 7: e35096

Kolar CS, Lodge DM (2001) Progress in invasion biology: predicting invaders. Trends Ecol Evol 16:199-204

- Levine JM (2000) Species diversity and biological invasions: relating local process to community pattern. Science 288: 852-854

Lockwood JL, Cassey P, Blackburn T (2005) The role of propagule pressure in explaining species invasions. Trends Ecol Evol 20:223-228

Lodge DM (1993) Biological invasions: lessons for ecology. Trends Ecol Evol 8:133-137

Lonsdale WM (1999) Global patterns of plant invasions and the concept of invasibility. Ecology 80:1522-1536

> Monteiro CA, Engelen AH, Santos ROP (2009a) Macro- and mesoherbivores prefer native seaweeds over the invasive brown seaweed Sargassum muticum: a potential regulating role on invasions. Mar Biol 156:2505-2515

Monteiro C, Engelen AH, Serrão EA, Santos R (2009b) Habitat differences in the timing of reproduction of the invasive alga Sargassum muticum (Phaeophyta, Sargassaceae) over tidal and lunar cycles. J Phycol 45:1-7

Monteiro CA, Engelen AH, Santos R (2012) Habitat-related differences in recruitment and survival of early recruits of the invasive Sargassum muticum (Phaeophyta, Sargassaceceae) in northern Portugal. Hydrobiologia 683: 287-296

Naeem S, Knops JMH, Tilman D, Howe KM, Kennedy T, Gale S (2000) Plant diversity increases resistance to invasion in the absence of covarying extrinsic factors. Oikos 91:97-108

Norton TA (1976) Why is Sargassum muticum so invasive? Br Phycol J 11:197-198

Norton TA (1981) Gamete expulsion and release in Sargas- sum muticum. Bot Mar 24:465-470

Olden JD, Poff NL (2004) Ecological processes driving biotic homogenization: testing a mechanistic model using fish faunas. Ecology 85:1867-1875

> Olden JD, Poff NL, Douglas MR, Douglas ME, Fausch KD (2004) Ecological and evolutionary consequences of biotic homogenization. Trends Ecol Evol 19:18-24

R Development Core Team (2010) R: a language and environment for statistical computing. R Foundation for Statistical Computing, Vienna

Sakai AK, Allendorf FW, Holt JF, Lodge DM and others (2001) The population biology of invasive species. Annu Rev Ecol Syst 32:305-332

Sousa WP (1979) Experimental investigations of disturbance and ecological succession in a rocky intertidal algal community. Ecol Monogr 49:227-254

> Stachowicz JJ, Bruno JF, Duffy EJ (2007) Understanding the effects of marine biodiversity on communities and ecosystems. Annu Rev Ecol Evol Syst 38:739-766

$>$ Stæhr PA, Pedersen MF, Thomsen MS, Wernberg T, KrauseJensen D (2000) Invasion of Sargassum muticum in Limfjorden (Denmark) and its possible impact on the indigenous macroalgal community. Mar Ecol Prog Ser 207: $79-88$

> Steneck RS, Dethier MN (1994) A functional group approach to the structure of algal-dominated communities. Oikos 69:476-498

$>$ Symstad AJ (2000) A test of the effects of functional group richness and composition on grassland invasibility. Ecology 81:99-109

Tilman D, Knops J, Wedin D, Reich P, Ritchie M, Siemann E (1997) The influence of functional diversity and composition on ecosystem processes. Science 277:1300-1302

Underwood AJ (1997) Experiments in ecology: their logical design and interpretation using analysis of variance. Cambridge University Press, Cambridge

Underwood AJ, Chapman MG (1998) GMAV5 for Windows. Institute of Marine Ecology, University of Sydney

Vadas RL, Johnson S, Norton TA (1992) Recruitment and mortality of early post-settlement stages of benthic algae. Eur J Phycol 27:331-351

Venables WN, Ripley BD (2002) Modern applied statistics with S, 4th edn. Springer, New York, NY

Vermeij GJ (1991) When biotas meet: understanding biotic interchange. Science 253:1099-1104

Viejo RM, Åberg P, Cervin G, Lindegarth M (1999) The interactive effects of adult canopy, germling density and grazing on germling survival of the rockweed Ascophyllum nodosum. Mar Ecol Prog Ser 187:113-120

> Vitousek PM, Mooney HA, Lubchenco J, Melillo JM (1997) Human domination of Earth's ecosystems. Science 277: 494-499

> White LF, Shurin JB (2007) Diversity effects on invasion vary with life history stage in marine macroalgae. Oikos 116: 1193-1203

Williamson M (1996) Biological invasions. Chapman \& Hall, New York, NY

Williamson M (2006) Explaining and predicting the success of invading species at different stages of invasion. Biol Invasions 8:1561-1568

Yendo K (1907) The Fucaceae of Japan. J Coll Sci Imp Univ Tokyo 21:1-174

Zuur AF, Ieno EN, Walker NJ, Saveliev AA, Smith GM (2009) Mixed effects models and extensions in ecology with R. Springer, New York, NY 